\title{
Quantitative Analysis on Influencing Factor of Per Capita Living Consumption Expenditure for Rural Residents - Based on empirical analysis in Jingmen City
}

\author{
Li Jiang \\ College of Economic and Management, Jingchu University of Technology, 448000, Jingmen \\ Hubei, China
}

\begin{abstract}
It is found that the per capita net income level of rural residents in Jingmen City influences the living consumption expenditure of rural residents, by quantitative analysis on the data of the specific items in the annual per capita living consumption expenditure, annual per capita net income and living consumption expenditure in rural families in Jingmen City based on mathematical model. In the structure of the consumption expenditure, the coefficient of the foods consumption ranks first, and the coefficient of the medical care consumption ranks second. Then three countermeasures and advises about increasing the consumption expenditure of rural residents are presented according to the analyzed result.
\end{abstract}

Keywords. rural residents; the structure of consumption; consumption expenditure

\section{Introduction}

In recent years, influenced by national macro-economic regulation and control and the policy, Jingmen City presented the problems about paying attention to agriculture continually. The living consumption level and living standard of peasants are obviously improved. The relevant data shows that in Jingmen City, the per capita net income of rural residents was 2980 yuan in 2000 , and the per capita net income was 7268 yuan in 2013. With the growth of the per capita net income, residents' living standard was improved greatly, the level of the per capita living consumption expenditure was increased continually; the structure of the consumption expenditure also changed. Nevertheless, the living consumption level of rural residents is far lower than that of the urban residents. The consumption expenditure of the rural residents grew slowly. The rural market lacks sufficient development. Jingmen City area, as one of the first sources of the rice cultivation culture in the world and having "China agriculture valley", its consumption level of rural residents is the important sign to measure the economic power in the area. It has an important and practical meaning to study the relation about the related factors of peasants per capita living consumption expenditure. The author thinks that it is necessary to analyze the per capita living consumption expenditure of rural residents and the structure of the consumption in Jingmen City, and explore the reasons behind, for finding out a certain rule. Accordingly, some advises are presented to increase the residents' living consumption expenditure, promote the structure of the peasants consumption, improve peasants' living standard and develop the rural economy in Jingmen City. However, in the real life, the qualitative analysis made only by experience and professional knowledge cannot satisfy the actual needs. We have to combine the qualitative 
analysis with quantitative analysis for classification. Therefore this article studies the phenomenon by using regression analysis in the quantitative analysis.

\section{Empirical analysis by using mathematical model}

This article analyzes the data (Form 1) of the annual per capita living consumption, the annual per capita net income and the foods, clothes, residence, home appliances, medical care and other items in the living consumption expenditure for the peasant families in Jingmen City from 2005 to 2013. According to the data, we establish the model, and select the parameters of the general model: $y$ is the per capita consumption expenditure, $x$ is the per capita net income, $\mathrm{x}_{1}$ is the food consumption, $\mathrm{x}_{2}$ is the clothes consumption, $\mathrm{x}_{3}$ is the residential consumption, $x_{4}$ is the home appliances, $x_{5}$ is the medical care consumption, $x_{6}$ is the traffic and communication consumption.

Table 1. Annual per capita net income and living expenditure of peasants in Jingmen City (Unit: yuan)

\begin{tabular}{|l|l|l|l|l|l|l|l|l|}
\hline Time & $\begin{array}{l}\text { Per capita } \\
\text { consump- } \\
\text { tion } \\
\text { expenditure }\end{array}$ & $\begin{array}{l}\text { Per capita } \\
\text { netincome }\end{array}$ & $\begin{array}{l}\text { Food } \\
\text { consump- } \\
\text { tion }\end{array}$ & $\begin{array}{l}\text { 2. Clothes } \\
\text { consump- } \\
\text { tion }\end{array}$ & $\begin{array}{l}3 . \\
\text { Residential } \\
\text { consumption }\end{array}$ & $\begin{array}{l}\text { Home } \\
\text { appliances }\end{array}$ & $\begin{array}{l}\text { Medical } \\
\text { care } \\
\text { consumption }\end{array}$ & $\begin{array}{l}\text { Traffic and } \\
\text { communicatio } \\
\text { n consumption }\end{array}$ \\
\hline 2005 & 3156 & 3738 & 1420 & 181 & 330 & 126 & 200 & 345 \\
\hline 2006 & 3327 & 4059 & 1515 & 190 & 357 & 181 & 176 & 387 \\
\hline 2007 & 3491 & 4652 & 1567 & 214 & 402 & 197 & 210 & 401 \\
\hline 2008 & 4534 & 5332 & 2024 & 228 & 483 & 583 & 286 & 397 \\
\hline 2009 & 4273 & 5956 & 1871 & 214 & 588 & 368 & 303 & 412 \\
\hline 2010 & 4786 & 6951 & 2063 & 264 & 618 & 468 & 382 & 421 \\
\hline 2011 & 5757 & 8248 & 2464 & 357 & 921 & 435 & 510 & 439 \\
\hline 2012 & 6608 & 9387 & 2621 & 426 & 1068 & 508 & 767 & 522 \\
\hline 2013 & 7268 & 10615 & 2870 & 474 & 1174 & 542 & 838 & 598 \\
\hline
\end{tabular}

Note: Data source: Statistical Yearbook of Jingmen City in 2014.

(1).Analysis on the features of the living consumption expenditure and net income, consumption of the peasants in Jingmen City

We know from analysis on the change in the living consumption expenditure and net income of the rural residents in Jingmen City from 2005 to 2013 through the statistical yearbook that the peasants' average annual net income grew fast year by year, increased from 3,738 yuan in 2005 gradually to 10,615 yuan in 2011, with an increase amplitude up to $183.97 \%$; Moreover, the peasants' average annual per capita living consumption expenditure also increased continually, from 3,156 yuan in 2005 to 7,268 yuan in 2013. The increase amplitude achieves $130.21 \%$. The peasants' net income in Jingmen City fits Keynes's hypothesis of absolute income. Namely, the income and expenditure are relevant in a short term. Consumption depends on income. Consumption will increase with the increase of the income, but the increase of the consumption is lower than that of the income. 


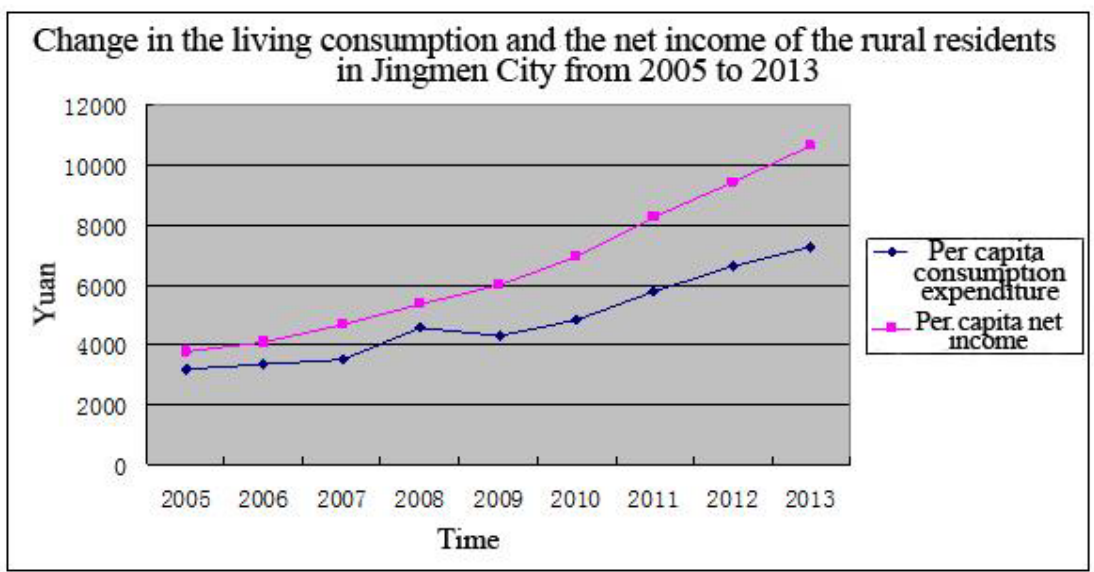

In order to reflect the data feature of peasants' living consumption expenditure in a more comprehensive way, we further analyzed the feature of the proportion of every element in the peasants consumption expenditure in the annual per capita living consumption expenditure of the peasants. The results of the data show that, the medical care expenditure has an obvious tendency of the increase by years in the peasants' per capita living consumption. Its proportion is increased from $6.33 \%$ to $11.53 \%$ in 2013 , with increase amplitude $82.14 \%$. While the food consumption expenditure has the largest proportion in the peasants' per capita living consumption, but its proportion has a trend of decrease by years, from $44.99 \%$ in 2005 to $39.48 \%$ in 2013 , with decrease amplitude of $12.24 \%$. The proportion of clothes expenditure, residential consumption expenditure and family consumption expenditure has an increase and decrease in the displayed data, but in a general increase trend. Its proportion is increased respectively from $5.73 \%, 10.46 \%$ and $3.99 \%$ in 2005 to $6.52 \%, 16.15 \%$ and $7.46 \%$ in 2013 . While the proportion of traffic and communication consumption expenditure, and cultural education and recreation consumption expenditure are decreased from $10.93 \%, 15.05 \%$ in 2005 to $8.23 \%, 7.58 \%$ in 2013 . The proportion of components of other goods and service presents a constant increasing trend, but due to its little proportion, its impact is little, too.

(2) Analysis on the correlation between per capita living consumption expenditure and net income for peasants in Jingmen City

It makes an analysis on the development tread of components of per capita living consumption expenditure, annual average net income and living consumption expenditure for peasants in Jingmen City. The research result shows that the per capita living consumption expenditure and annual average net income for peasants in Jingmen City has a trend of increase by years. In the components of per capita living consumption expenditure, the proportion of peasant's food consumption expenditure, traffic, communication, cultural education and recreation in the annual per capita living consumption expenditure for peasant has a trend of decrease by years, while the proportion of medical care expenditure, clothes consumption expenditure, residential consumption expenditure and family consumption expenditure has a trend of increase. To make a clear analysis on the impact of annual per capita net income and living consumption expenditure on peasant's income, this article applies Eviews software and quantitative economic model for detailed analysis.

Consider the relation of living consumption expenditure and net income for rural residents in Jingmen City from 2005 to 2013, and apply the mathematical tools to establish a model for annual per capita living consumption expenditure y (dependent variable) and annual per capita net income $\mathrm{x}$ (independent variable) for peasant, as well as make unitary linear regression analysis to get a unitary linear regression equation $y=0.5978 x+885.52$. It is known from the regression analysis result that $R^{2}=0.9793, R=0.989578$, indicating that the per capita net income is in positive correlation with the per capita consumption, and the fitting degree of regression equation is relatively desirable. $\mathrm{F}=330.5761$, the value of $\mathrm{F}$ is relatively significant, and the regression 
equation is highly significant. Economically, it complies with the regularity of marginal consumption propensity that lies within $0-1$, which indicates that from 2005 to 2012, each increase of 1 yuan in annual per capita net income for rural residents in Jingmen City will lead to annual increase of 0.5978 yuan in annual per capita living consumption expenditure of peasants. It shows that the per capita net income has a great impact on per capita living consumption expenditure.

(3)Establishment and analysis of multiple regression model about per capita living consumption expenditure and its components for peasants

In the actual life, the peasant's consumption expenditure will not only be affected by income, but also by other components. The components of living consumption expenditure of peasants include food consumption, clothes consumption, residential consumption, home appliances, medical care consumption, traffic and communication consumption, cultural education and recreation, and other goods and services. We use the mathematical software to make multiple linear regression analysis on food consumption, clothes consumption, residential consumption, home appliances and medical care consumption.

\begin{tabular}{|l|l|l|l|l|l|l|l|}
\multicolumn{1}{c}{$y=1.9371 x_{1}-0.5903 x_{2}-0.087 x_{3}+0.057 x_{4}+2.017 x_{5}+0.919 x_{6}-189.078$} \\
\hline t Stat & -16.5511 & 129.0309 & -14.0022 & -5.14946 & 4.030195 & 146.9586 & 67.42388 \\
\hline P-value & 0.003631 & $6.01 \mathrm{E}-05$ & 0.005062 & 0.035704 & 0.056408 & $4.63 \mathrm{E}-05$ & 0.00022 \\
\hline
\end{tabular}

It is known from the regression analysis that the goodness of fit for the regression equation $R^{2}=1$ is relatively desirable, and each explanatory variable generally has a significant explanatory effect and highly linear impact on $y$. As the regression coefficients $x_{2}$ and $x_{3}$ is not reasonable, in the inspection of $\mathrm{t}$, we get $t_{4}<4.303$, and the value of $\mathrm{P}$ for explanatory variables $\mathrm{x}_{1}$ and $\mathrm{x}_{5}$ is larger than 0.05 , from which we may conclude that there is probably multicollinearity problem among the independent variables. We may use stepwise regression method for calibration, and a multiple linear regression equation after deleting the variables $\mathrm{x}_{2}, \mathrm{x}_{3}$ and $\mathrm{x}_{4}$ :

$$
\begin{aligned}
& y=1.931708 x_{1}+1.711 x_{5}+0.8733 x_{6}-231.349 \\
& R^{2}=0.99995, \mathrm{~F}=16750.7
\end{aligned}
$$

From the above analysis, we find that the per capita net income level of rural residents in Jingmen City affects the living consumption expenditure of rural residents. In other words, the improvement of per capita net income level of rural residents will facilitate the increase of consumption expenditure of rural residents. Inside the consumption expenditure structure, the consumption coefficient of food ranks first, and that of medical care ranks second, indicating that with the development of national economic level and the improvement of peasant's income level, the consumption structure of rural residents still have a large proportion in medical care, food and other aspects related to daily necessities, while have a less proportion in clothes, which also indicates an extensive market of medical care and food industry in rural area. Compared to the past, the expenditure is apparently increased in the traffic and communication, and it mainly depends on the construction of "connecting-all-villages" road in the rural area recently.

\section{Measure and advice to improve the consumption expenditure of rural residents}

(1) As the per capita net income has a significant impact on the per capita living consumption expenditure, the net income of peasant shall be greatly improved, so that their consumption basis can be strengthened. There are many ways to increase the peasant's income, for example, we may facilitate the agricultural industrialization and improve the agricultural production level; positively develop organic agriculture and green produce; deep process the produce to improve its productivity and increase its added value; invest more on the construction of infrastructure and 
ecological environment protection to ensure the sustainable development of agriculture; stabilize the price of produce, normalize the agricultural material market, invest more on agricultural support; transfer the residual labor force in rural area, encourage autonomous start-up of business; properly improve the income level for low-income group. Only in this way can the net income of peasant's family be improved efficiently, and the per capita living consumption level increased. The increase of net income will lead to increase of consumption, and the increase of consumption will bring about the increase of economy.

(2) It is known from the analysis on the model that the consumption in medical care accounts for a large proportion in the living consumption for peasant. So if we want the peasant, one of the disadvantaged groups with weakest security in the modern market economy, to make consumption without concern, we shall greatly develop the rural social undertakings, and shall establish and perfect the rural social security system. Apart from establishing a perfect rural health care and medical system, we may also set up a perfect rural endowment insurance, lowest life guarantee system, legal aid system, residence for people in distress and other social assistance systems. Only the perfection of rural social security system will reduce the saving awareness and behavior of peasant against the future consumption, increase the consumption confidence of peasant and expand their current consumption.

(3) Optimize the consumption structure of rural residents and guide them to set up a proper and positive value of consumption. With the development of national economy and the general improvement of income level for peasants, the rural consumption expenditure structure also experienced significant adjustment and change. The consumption expenditure no longer concentrates on the clothes, food and other "survival type" products. We shall positively guide the peasant to set up the consumption values of composite economy and cultural development, and facilitate the sustainable development of rural economy. We may also improve the educational level in rural area to change the consumption idea of peasant, so as to improve their consumption level.

\section{Acknowledgement}

This program was funded by Development \&Research Center for China Agriculture Valley.

\section{References}

1. Liang, H.O., Wang, J., Xuan, Y.S., Tao, P.J. Analysis on ELES Model about the Consumption Demand of Rural Residents in Hebei Province [J]. Guangdong Agricultural Science, 2011(9).

2. Xiao, T.T.; Research on the Consumption Structure of Rural Residents in Henan Province [D]. Northwest A\&F University, 2011.

3. Zheng, Y.L.; Research on the Consumption Structure of Rural Residents in Ningxia [D]. Northwest A\&F University, 2011.

4. Zhu, S.; Research on the Current Change Trend of Consumption Demand Structure of Rural Residents in China [D]. Hunan Normal University, 2008.

5. Hu, J.W., Chen, T.X.; Quantitative Analysis on Income and Consumption of Rural Residents in China [J]. Rural Economy and Science, 2007(1). 